\title{
New Books - Livres nouveaux - Neue Bücher
}

C. V. Ramakrishnan (Ed.): Tissue Culture. Proc. Seminar, Baroda, India 1965. W. Junk, Den Haag 1965. XVI+430 pp., 86 figs. Gebunden. Preis: US \$ 19.40.

Gewebezüchtung ist nicht eine Wissenschaft für sich, sondern eine Forschungs-methode, die auf verschiedenen Gebieten neue, wertvolle Ergebnisse gezeitigt hat, so z.B. in der Zytologie, Embryologie, Genetik, Histophysiologie und -pharmako-logie, Endokrinologie, Biochemie, experimentellen Pathologie und Onkologie, Viro-logie, Immunologie usw. Das wird auch angedeutet durch die im Buch zusammen-gefaßten Vorträge, gehalten an einem 1965 in Baroda (Indien) durchgeführten Seminar, welches Wissenschaftler dieses Landes mit Technik und Möglichkeiten der Gewebekultur sowie mit auf diesem Gebiet bewährten Forschern anderer Konti-nente näher bekannt machen sollte (von den 88 Teilnehmern kamen je etwa ein halbes Dutzend aus Großbritannien, Nordamerika und Japan). Ungefähr 5/8 des Buches sind der Kultur tierischer Zellen und Organe sowie der Virologie gewidmet (Part I. Animal Tissue Culture: Section I. Organ and Explant Culture, 77 Seiten; II. Cell Culture, 116 S.; III. Tissue Culture in Virology, 48 Seiten), etwa 3/8 der Züchtung von Pflanzengeweben (Part II. Plant Tissue Culture, 156 Seiten), die dem Mediziner natürlich etwas ferner liegt. Technische Fragen werden in der Regel ausführlich besprochen. Die Diskussionsbeiträge sind nicht berücksichtigt. Von den 22 Vorträgen über Zell- und Organkultur stammen 15 von den auswärtigen Gästen, sehr inhaltsreiche Vorträge, die in konzentrierter Form Wesentliches aussagen, dem europäischen oder amerikanischen Spezialisten jedoch nicht besonders viel Neues bringen, dem Nichtspezialisten indessen eine schöne Ubersicht über verschiedene Anwendungsgebiete der Kultur in vitro zu geben vermögen. Besonders interessiert haben uns die indischen Beiträge - 7 in den ersten beiden Abschnitten, sämtliche 7 im Abschnitt Virologie und 14 von 16 im zweiten Teil des Buches -, da sie uns einen, wenn auch nur fragmentarischen und durch die Auswahl der Seminarteil-nehmer vielleicht etwas zufälligen Einblick vermitteln in das, was in jenem Land auf dem Gebiet der Gewebezüchtung geschieht (dazu tragen auch die hinzugefügten Literaturangaben bei). Das Buch wird in jedem Institut, das sich mit Gewebezüchtung befaßt, ohne Zweifel wertvolle Dienste leisten.

Otto Bucher (Lausanne) 